\title{
In vivo imaging of vulnerable plaque with intravascular modalities: its advantages and limitations
}

\author{
Satoshi Kitahara ${ }^{1}$, Yu Kataoka ${ }^{1}$, Hiroki Sugane ${ }^{2}$, Fumiyuki Otsuka ${ }^{1}$, Yasuhide Asaumi ${ }^{1}$, Teruo Noguchi ${ }^{1}$, \\ Satoshi Yasuda ${ }^{1}$ \\ ${ }^{1}$ Department of Cardiovascular Medicine, National Cerebral \& Cardiovascular Center, Suita, Osaka, Japan; ${ }^{2}$ Department of Cardiovascular \\ Medicine, Chikamori Hospital, Kochi, Japan \\ Contributions: (I) Conception and design: Y Kataoka; (II) Administrative support: S Yasuda; (III) Provision of study materials or patients: Y Kataoka, S \\ Kitahara; (IV) Collection and assembly of data: Y Kataoka, S Kitahara; (V) Data analysis and interpretation: Y Kataoka, S Kitahara; (VI) Manuscript \\ writing: All authors; (VII) Final approval of manuscript: All authors. \\ Correspondence to: Yu Kataoka, MD, PhD. Department of Cardiovascular Medicine, National Cerebral and Cardiovascular Center, 6-1, Shinmachi, \\ Kishibe, Suita, Osaka, 564-8565, Japan. Email: yu.kataoka@ncvc.go.jp.
}

\begin{abstract}
In vivo imaging of plaque instability has been considered to have a great potential to predict future coronary events and evaluate the stabilization effect of novel anti-atherosclerotic medical therapies. Currently, there are several intravascular imaging modalities which enable to visualize plaque components associated with its vulnerability. These include virtual histology intravascular ultrasound (VH-IVUS), integrated backscatter IVUS (IB-IVUS), optical coherence tomography (OCT), near-infrared spectroscopy and coronary angioscopy. Recent studies have shown that these tools are applicable for risk stratification of cardiovascular events as well as drug efficacy assessment. However, several limitation exists in each modality. The current review paper will outline advantages and limitation of VH-IVUS, IB-IVUS, OCT, NIRS and coronary angioscopy imaging.
\end{abstract}

Keywords: Vulnerable plaque; intravascular imaging; virtual-histology intravascular ultrasound (VH-IVUS); optical coherence tomography (OCT); near-infrared spectroscopy (NIRS); integrated backscatter intravascular ultrasound (IB-IVUS), coronary angioscopy

Submitted Feb 15, 2020. Accepted for publication Apr 20, 2020.

doi: $10.21037 / \mathrm{cdt}-20-238$

View this article at: http://dx.doi.org/10.21037/cdt-20-238

\section{Introduction}

An insignificant but prone-to-rupture coronary lesion has been named as "vulnerable plaque" (1). To elucidate the nature and mechanism of vulnerable plaque, numerous pathohistological studies have been conducted, and findings from these studies have considerably contributed to the understanding of the pathophysiology of vulnerable plaque (2-8). Meticulous analyses of coronary specimen have characterized vulnerable plaque which include a large lipid core, thin fibrous cap, expansive vessel remodeling and macrophage infiltration (2-8). These collective evidences emerge the notion that identification of vulnerable plaque with imaging modality would enable to predict the occurrence of acute coronary syndrome (ACS) and commence effective preventive therapies.

In 1990, grey-scale intravascular ultrasound (IVUS) has been developed and then used mainly for the guidance of percutaneous coronary intervention (PCI) procedures (9). One of advantages of grey-scale IVUS imaging is that it provides quantitative analysis of plaque volume in vivo. This helps interventionalists to select the optimal size of devices. In addition, grey-scale IVUS has become a tool to evaluate drug efficacy due to its quantitative and reproducible features. With regard to the ability of grey-scale IVUS for visualization of vulnerable plaques, pathohistological and clinical studies reported that attenuation of ultrasonic signals corresponds to the presence of necrotic core. 
However, recent study showed that the positive predictive value of IVUS for detecting thin-cap fibroatheroma (TCFA) was only $19 \%$ (10). Due to this limitation of IVUS, another intravascular imaging devices which visualizes plaque quality has been developed. In this review, we will summarize advantages and limitation to image vulnerable plaques with currently available modalities: virtual-histology IVUS (VHIVUS), integrated backscatter IVUS (IB-IVUS), optical coherence tomography (OCT), near-infrared spectroscopy (NIRS) and coronary angioscopy.

\section{VH-IVUS}

\section{Tissue characterization with VH-IVUS}

VH-IVUS utilizes radiofrequency analysis of reflected ultrasound signals in a frequency domain analysis (11). It determines four tissue components: fibrous, fibrofatty, necrotic core and dense calcium. A reconstructed colorcoded tissue map of plaque composition is provided and superimposed on each frame of greyscale IVUS.

\section{Validation of VH-IVUS imaging}

In one analysis of autopsy specimens, the accuracy of the VH-IVUS for predicting the aforementioned 4 tissue types was $79.7 \%, 81.2 \%, 85.5 \%$ and $92.8 \%$ for fibrous, fibrofatty, necrotic cores and calcium, respectively (11). Similarly, another analysis of culprit lesions in subjects who underwent PCI with directional coronary atherectomy has reported that VH-IVUS imaging identified fibrous, fibrofatty, necrotic cores and calcium with a satisfactory accuracy $(87.1 \%, 87.1 \%, 88.3 \%$ and $96.5 \%$, respectively) (12).

Brown et al. investigated the ability of VH-IVUS to detect TCFA by comparing with histology (13). This study showed that the diagnostic accuracy and sensitivity of TCFA on VH-IVUS was 76.5 and $83.6 \%$, respectively. In this analysis, VH-IVUS classified 7 of 8 TCFAs as thick-cap fibroatheroma. This suggests that VH-IVUS is capable of identifying a large necrotic core, but is limited to correctly evaluate thin fibrous cap.

\section{The ability of VH-IVUS for future cardiovascular events}

Given that plaque containing greater quantities of both necrotic and lipidic material confer an increased risk of cardiovascular events, there has been considerable interests whether VH-IVUS could predict future risks of cardiovascular events (Tables 1,2). The PROSPECT (The Providing Regional Observations to Study Predictors of Events in the Coronary Tree) trial is the largest observational study which investigated the predictive ability of TCFA on VH-IVUS for cardiovascular events (14). This study enrolled a total of 697 ACS patients. All three major coronary arteries were imaged by VH-IVUS. VH-IVUSderived TCFA was defined as more than 30 degrees of the necrotic core abutted the lumen in 3 or more consecutive frames. In this study, $596 \mathrm{VH}-\mathrm{IVUS}$ derived TCFA were identified in 313 patients. During a median follow-up period of 3.4 years, patient-level analysis demonstrated VH-IVUS derived TCFA as an independent predictor of subsequent non-culprit lesion-related major adverse cardiovascular events (MACEs) [hazard ratio $(\mathrm{HR})=3.35$, $95 \%$ confidence interval $(\mathrm{CI}): 1.77-6.36, \mathrm{P}<0.001]$, in addition to insulin-requiring diabetes $(\mathrm{HR}=3.32,95 \% \mathrm{CI}$ : 1.43-7.72, $\mathrm{P}=0.005$ ), baseline plaque burden $>70 \%$ ( HR $=5.03,95 \%$ CI: $2.51-10.11, \mathrm{P}<0.001)$ and a minimal luminal area $\leq 4.0 \mathrm{~mm}^{2}$ (HR $=3.21,95 \%$ CI: $1.61-6.42, \mathrm{P}=0.001$ ). Similar findings were observed even at lesion-level analysis. Of note, the frequency of non-culprit lesion-related MACE increased in association with the number of these $\mathrm{VH}$ IVUS derived measures (no feature: $0.3 \%, 1$ feature: $4.8 \%$, 2 features: $10.5 \%, 3$ features; $18.2 \%, \mathrm{P}<0.001$ ).

The VIVA (VH-IVUS in Vulnerable Atherosclerosis) study analyzed the association of VH-IVUS derived plaque features with clinical outcomes in patients with coronary artery disease (CAD) (15). Three major coronary arteries in 170 patients with CAD were monitored by VH-IVUS. Compared to PROSPECT study, this study used different definition of VH-IVUS derived TCFA, which included plaque burden $>40 \%$ and confluent necrotic core $>10 \%$ plaque cross-sectional area, in contact with vessel lumen for 3 consecutive frames. In this study with a median follow-up of 625 days, both patient-based and lesion-based analyses elucidated that VH-IVUS-derived TCFA was the only plaque phenotype associated with the occurrence of MACE (patient-based analysis: HR $=7.53,95 \%$ CI: 1.12-50.55, $\mathrm{P}=0.038$, lesion-based analysis: $\mathrm{HR}=4.43,95 \% \mathrm{CI}: 1.50$ 13.18, $\mathrm{P}=0.007)$.

The ATHEROREMO-IVUS (the European Collaborative Project on Inflammation and Vascular Wall Remodeling in Atherosclerosis-Intravascular Ultrasound) study is a single-center observational study of 581 ACS or stable CAD subjects (16). VH-IVUS was used to interrogate non-culprit vessel. The primary outcome was the occurrence of MACE which included non-culprit lesion 
Table 1 Clinical studies with VH-IVUS imaging-prediction of future cardiovascular events

\begin{tabular}{|c|c|c|c|c|}
\hline Authors & Sites & Population & VH-IVUS-derived measure & Findings \\
\hline $\begin{array}{l}\text { Calvert } \\
\text { et al. } \\
(15)\end{array}$ & $\begin{array}{l}\text { One site } \\
\text { in United } \\
\text { Kingdom }\end{array}$ & $\begin{array}{l}170 \text { patients with } \\
\text { CAD }(A C S=70 \text {, } \\
\text { stable } C A D=100)\end{array}$ & $\begin{array}{l}\text { TCFA defined by VH-IVUS: } \\
\text { plaque burden }>40 \% \text {, confluent } \\
\text { necrotic core }>10 \% \text {; plaque } \\
\text { cross-sectional area, in } \\
\text { contact with vessel lumen for } 3 \\
\text { consecutive frames }\end{array}$ & $\begin{array}{l}\text { During a median follow-up of } 625 \text { days, VH-IVUS-derived TCFA } \\
\text { was a plaque feature associated with the occurrence of major } \\
\text { adverse cardiovascular events (patient-based analysis: HR } \\
=7.53,95 \% \mathrm{Cl}: 1.12-50.55, \mathrm{P}=0.038 \text {, lesion-based analysis: HR } \\
=4.43,95 \% \mathrm{Cl}: 1.50-13.18, \mathrm{P}=0.007 \text { ) }\end{array}$ \\
\hline
\end{tabular}

ACS, acute coronary syndrome; CAD, coronary artery disease; Cl, confidence interval; HR, hazard ratio; VH-IVUS, virtual histologyintravascular ultrasound.

related or indeterminate mortality, ACS or unplanned coronary revascularization. In this study, the presence of TCFA (HR $=1.98,95 \% \mathrm{CI}: 1.09-3.60, \mathrm{P}=0.02)$ and plaque burden $>70 \%$ (HR $=2.90,95 \%$ CI: $1.60-5.25$, $\mathrm{P}<0.001)$ predicted the occurrence of MACE. Interestingly in particular, the presence of TCFA with plaque burden $>70 \%$ was associated with an elevated risk of MACE within $(\mathrm{P}=0.011)$ and after 6 months $(\mathrm{P}<0.001)$.

Serial VH-IVUS imaging has provided insights into the natural history of atheroma instability. Kubo et al. reported changes in a variety of plaque phenotypes in 99 patients (20). There were 20 TCFA at baseline. During the follow-up period, its healing was observed in $75 \%$ of them. Namely, 13 and 2 TCFAs became thick-cap fibroatheroma and fibrous plaque, respectively. Furthermore, the remaining $25 \%$ of TCFAs did not change. In this analysis, 12 newly developed TCFAs were observed. This vulnerable feature occurred at pathological intimal thickening or thick-cap fibroatheroma at baseline. As such, serial VHIVUS imaging elucidated the formation of TCFA and its spontaneous healing in vivo. This observation suggests that all TCFA does not necessarily cause coronary event but remains quiescent.

\section{Drug efficacy assessment study with VH-IVUS (Tables 1,2)}

Nasu et al. compared serial change in plaque composition on VH-IVUS between stable CAD patients receiving fluvastatin and those without it for 12 months (17). Under the therapy, LDL-C level was significantly lowered by $98.1 \pm 12.7 \mathrm{mg} / \mathrm{dL}$. Additionally, the use of fluvastatin was associated with favourable modulation of plaque components, reflected by a significant reduction of fibro-fatty volume $\left(80.1 \pm 57.9 \mathrm{~mm}^{3}\right.$ at baseline $v s .32 .5 \pm 27.7 \mathrm{~mm}^{3}$ at followup, $\mathrm{P}<0.0001)$ and a significant increase in fibrous tissue volume $\left(146.5 \pm 85.6 \mathrm{~mm}^{3}\right.$ at baseline vs. $163.3 \pm 94.5 \mathrm{~mm}^{3}$ at follow-up, $\mathrm{P}<0.0001)$. In contrast to these findings, in patients who did not receive fluvastatin, a significant increase in volumes of fibro-fatty, necrotic core and calcium materials was observed. Linear regression analysis identified the relationship of changes in LDL-C $(\mathrm{R}=0.703, \mathrm{P}<0.0001)$ and high-sensitivity c-reactive protein levels $(\mathrm{R}=0.357$, $\mathrm{P}=0.006$ ) with change in fibro-fatty volume.

The SATURN (The Study of Coronary Atheroma by Intravascular Ultrasound: Effect of Rosuvastatin Versus Atorvastatin) trial is a largest serial IVUS study which compared two high-intensity statin regimens on coronary 
Table 2 Clinical studies with VH-IVUS imaging-evaluation of drug efficacy

\begin{tabular}{|c|c|c|c|c|}
\hline Authors & Subjects & Therapy & Outcomes & Findings \\
\hline $\begin{array}{l}\text { Puri } \\
\text { et al. (18) }\end{array}$ & $\begin{array}{l}71 \text { subjects } \\
\text { with } C A D\end{array}$ & $\begin{array}{l}80 \mathrm{mg} \\
\text { atorvastatin } \\
\text { vs. } 20 \mathrm{mg} \\
\text { rosuvastatin }\end{array}$ & $\begin{array}{l}\text { Change in } \mathrm{VH}- \\
\text { IVUS derived plaque } \\
\text { composition }\end{array}$ & $\begin{array}{l}\text { High-intensity statin use was associated with a reduction in fibro-fatty } \\
\text { tissue volume }(P<0.001) \text { and an increase in dense calcium tissue volume } \\
(P=0.002)\end{array}$ \\
\hline $\begin{array}{l}\text { Räber } \\
\text { et al. (19) }\end{array}$ & $\begin{array}{l}82 \text { STEMI } \\
\text { patients }\end{array}$ & $\begin{array}{l}10 \mathrm{mg} \\
\text { rosuvastatin }\end{array}$ & $\begin{array}{l}\text { Change in percent } \\
\text { atheroma volume and } \\
\text { VH-IVUS derived plaque } \\
\text { composition }\end{array}$ & $\begin{array}{l}\text { During the } 13-\text { month follow-up period, } 10 \mathrm{mg} \text { rosuvastatin induced a } \\
\text { significant reduction of percent atheroma volume }[-0.9 \%(95 \% \mathrm{Cl} \text { : } \\
\text { e-1.56\% to }-0.25 \%, \mathrm{P}=0.007)] \text {. In addition, an increased percent volume } \\
\text { of dense calcium }[+1.28 \%(95 \% \mathrm{Cl}: 0.66 \% \text { to } 1.9 \%), \mathrm{P}<0.001] \text { and a } \\
\text { decrease in percent volume of fibrous tissue }[-1.38 \%(95 \% \mathrm{Cl}:-2.28 \text { to } \\
-0.47), \mathrm{P}=0.003] \text { were observed. This therapy did not significantly modify } \\
\text { volume of necrotic core }[-0.05 \%(95 \% \mathrm{Cl}:-1.05 \text { to } 0.96), \mathrm{P}=0.926]\end{array}$ \\
\hline
\end{tabular}

ACS, acute coronary syndrome; CAD, coronary artery disease; Cl, confidence interval; HR, hazard ratio; VH-IVUS, virtual histologyintravascular ultrasound.

atherosclerosis in 1039 stable CAD patients (21). Serial VH-IVUS imaging was used in 71 patients for sub-analysis of analyzing plaque stabilization effects of high-intensity statin (18). Fibro-fatty tissue volume significantly reduced (23.1 to $13.4 \mathrm{~mm}^{3}, \mathrm{P}<0.001$ ) and calcium tissue volume increased (1.2 to $\left.2.1 \mathrm{~mm}^{3}, \mathrm{P}=0.002\right)$. In addition, on lesionbased analysis, the use of high-intensity statin reduced the number of pathological intimal thickening lesions (67\% vs. $38 \%, \mathrm{P}=0.001)(18)$.

IBIS-4 (Integrated Biomarker Imaging Study-4) study investigated the effect of $10 \mathrm{mg}$ rosuvastatin of atheroma progression and VH-IVUS derived plaque components in 146 non-infarct-related coronary arteries of 82 STEMI patients (19). Predictably, $10 \mathrm{mg}$ rosuvastatin significantly lowered LDL-C level (median: 127 vs. $73 \mathrm{mg} / \mathrm{dL}, \mathrm{P}<0.001$ ) with an increase in HDL-C level (median: 42 vs. $46 \mathrm{mg} / \mathrm{dL}$, $\mathrm{P}<0.001)$ during the 13 -month follow-up period. Moreover, a significant reduction of percent atheroma volume was observed under this therapeutic regimen $[-0.9 \%$ (95\% CI: $-1.56 \%$ to $-0.25 \%, \mathrm{P}=0.007)]$. While $10 \mathrm{mg}$ rosuvastatin was associated with an increased percent volume of dense calcium [1.28\% (95\% CI: $0.66 \%$ to $1.9 \%), \mathrm{P}<0.001]]$ and a decrease in percent volume of fibrous tissue $[-1.38 \%(95 \%$ CI: $-2.28 \%$ to $-0.47 \%), \mathrm{P}=0.003]$, it did not affect necrotic core $[-0.05 \%$ (95\% CI: $-1.05 \%$ to $0.96 \%$ ), $\mathrm{P}=0.926$ ], which was inconsistent to that in other pre-clinical and pathohistological studies. Relatively short follow-up period (12-18 months) may make it difficult to detect favourable efficacy of a statin on modifying necrotic core in vivo.

\section{Consideration of limitation of VH-IVUS imaging}

Recent data raise questions about the accuracy of VH-IVUS to detect necrotic core. In a swine atherosclerosis model, there was no correlation between VH-IVUS-identified necrotic core and histology (22). Swine necrotic core lack cholesterol crystals, making them inherently different from human necrotic cores. However, this data arise concern to use VH-IVUS imaging for drug efficacy assessment trial. The GLAGOV (Global Assessment of Plaque Regression With a PCSK9 Antibody as Measured by Intravascular Ultrasound) trial is a recent IVUS study to investigate anti-atherosclerotic property of evolocumab injection on coronary atheroma in 968 stable CAD patients who have already been treated with tolerable maximally intensity statin (23). This trial demonstrated that evolocumab induced greater regression of coronary atherosclerosis. VH-IVUS was used as sub-study in 331 patients (24). Even in this cohort, reduction of LDL-C levels and regression of coronary atheroma was observed with similar extent to main findings of the GLAGOV trial. Despite these favourable observations, there were no significant differences in VH-IVUS derived plaque components [calcium $(1.0 \pm 0.3$ vs. $\left.0.6 \pm 0.3 \mathrm{~mm}^{3}, \mathrm{P}=0.49\right)$, fibrous $\left(3.0 \pm 0.6\right.$ vs. $2.4 \pm 0.6 \mathrm{~mm}^{3}$, $\mathrm{P}=0.49)$, fibrofatty $\left(5.0 \pm 1.0\right.$ vs. $\left.3.0 \pm 1.0 \mathrm{~mm}^{3}, \mathrm{P}=0.49\right)$, and necrotic $\left(0.6 \pm 0.5\right.$ vs. $\left.\left.0.1 \pm 0.5 \mathrm{~mm}^{3}, \mathrm{P}=0.49\right)\right]$ volumes 
between evolocumab and control groups. The lack of any demonstrable differences between the treatment groups in VH-IVUS analysis of the GALOGOV trial suggests the limitation of VH-IVUS for drug efficacy assessment trial.

The acquisition of VH-IVUS images is gated at the $\mathrm{R}$ wave of the electrocardiography signal, which fails to allow for VH-IVUS imaging to be performed upon the frames acquired within each R-R interval. Variability in a patient's heart rate at different time points results in a degree of horizontal bias during serial VH-IVUS imaging. These cause different numbers of frames at baseline and follow-up imaging, which is not adequate for analyzing the exactly same segment in the clinical trials of drug efficacy evaluation.

\section{IB-IVUS}

\section{Tissue characterization and validation of IB-IVUS imaging}

IB-IVUS is another imaging modality to evaluate compositional features of coronary atheroma in vivo. This imaging technique utilizes time-domain information through the acquired radiofrequency signals (25). Ex vivo validation study showed that IB signals could differentiate different types of plaque tissues including fibrous, calcification and lipid pool. The accuracy of IB-IVUS to detect fibrous, lipid-rich and fibrocalcific plaques was $93 \%$, $90 \%$ and $96 \%$, respectively $(25,26)$. Another study reported that the positive predictive value of IB-IVUS for TCFA was $50.0 \%(27)$.

\section{Drug efficacy assessment study with IB-IVUS (Table 3)}

Kawasaki, et al. compared 6-month changes in IB-IVUS derived plaque features in 52 patients with pravastatin, atorvastatin or diet therapy (28). Non-culprit segment was selected for this analysis. On serial IB-IVUS imaging, the use of pravastatin and atorvastatin was associated with a significant increase in fibrous volume and a reduction of lipid volume compared to subjects receiving diet therapy. Similar findings were reported by another study analyzing 42 patients with stable CAD (29). Following the 9-month $4 \mathrm{mg}$ pitavastatin use, a significant increase in fibrous volume index $(\mathrm{P}=0.01)$ and as well as a significant decrease in lipid volume index $(\mathrm{P}=0.03)$ were observed. Details in other studies with IB-IVUS for the assessment of drug efficacy are summarized in Table 3 (30-35).

\section{Consideration of limitation of IB-IVUS imaging}

Evidence is limited to show the association of IB-IVUS derived plaque features with cardiovascular events.

\section{OCT imaging}

\section{Imaging of plaque microstructures}

OCT uses near-infrared light which enables to provide imaging of atherosclerotic plaques in coronary artery $(36,37)$. High resolution imaging is one of the advantages of OCT imaging. Its resolution is up to $10 \mu \mathrm{m}$ in an axial resolution and to $20 \mu \mathrm{m}$ in a lateral resolution, which is approximately 10 times higher compared to that of IVUS. This distinct feature of OCT enables to generate high quality imaging of plaque microstructures such as thin fibrous cap, microchannel, accumulation of lipid and macrophages $(36,37)$.

There are numerous studies which elucidated features of plaque microstructures in patients with CAD. In 30 subjects with acute myocardial infraction, thin fibrous cap, plaque rupture, thrombus and TCFA were observed, in line with findings from pathohistological studies (38). In another study, the presence of vaso vasorum at culprit lesions was associated with thinner fibrous cap, a higher frequency of TCFA and a higher c-reactive protein level (39). OCT has been shown to identify differences in plaque features of subjects with ST-elevation myocardial infarction, nonST-elevation ACS and stable angina pectoris (37). TCFA was defined as a plaque with lipid arc $>90$ degrees and its fibrous cap thickness $<65 \mu \mathrm{m}$. The frequency of TCFA was significantly higher in patients with ST-elevation myocardial infarction and non-ST-elevation ACS compared to that in subjects with stable angina pectoris $(72 \%, 50 \%$, and $20 \%$, respectively, $\mathrm{P}=0.012$ ). Furthermore, patients with ST-elevation myocardial infarction and non-ST-elevation ACS were more likely to exhibit thinner fibrous cap (47.0, 53.8 and $102.6 \mu \mathrm{m}$, respectively, $\mathrm{P}=0.034)$.

\section{Validation of OCT imaging}

Ex vivo validation study has been conducted to compare OCT images with histological features by using 357 atherosclerotic arterial segments of autopsy specimens (40). Fibrous plaques were characterized by homogeneous, signal-rich regions. Fibrocalcific plaques was defined as well-delineated, signal-poor regions with sharp borders. Lipid-rich plaques was characterized by signal-poor regions 
Table 3 Clinical studies with IB-IVUS imaging-evaluation of drug efficacy

\begin{tabular}{|c|c|c|c|c|}
\hline Authors & Subjects & Therapy & Outcomes & Findings \\
\hline $\begin{array}{l}\text { Otagiri } \\
\text { et al. (30) }\end{array}$ & $\begin{array}{l}20 \mathrm{ACS} \\
\text { patients }\end{array}$ & $5 \mathrm{mg}$ rosuvastatin & $\begin{array}{l}\text { Volumetric change } \\
\text { in calcified, } \\
\text { fibrous and lipid } \\
\text { components }\end{array}$ & $\begin{array}{l}\text { Changes in calcified and fibrous volume did not differ under the } \\
6 \text {-month rosuvastatin use (calcified volume: } P=0.06 \text {, fibrous volume: } \\
P=0.38) \text {. By contrast, this therapeutic regimen reduced lipid volume } \\
(P<0.001)\end{array}$ \\
\hline $\begin{array}{l}\text { Niki } \\
\text { et al. (32) }\end{array}$ & $\begin{array}{l}95 \text { CAD } \\
\text { patients }\end{array}$ & $\begin{array}{l}\text { Statin alone vs. } \\
\text { statin }+1,800 \mathrm{mg} \\
\text { EPA }\end{array}$ & $\begin{array}{l}\text { Change in IB-IVUS } \\
\text { derived plaque } \\
\text { components }\end{array}$ & $\begin{array}{l}\text { EPA use was associated with a significant reduction in lipid volume } \\
(P=0.007) \text { and a significant increase in fibrous volume }(P=0.01)\end{array}$ \\
\hline $\begin{array}{l}\text { Kuramitsu } \\
\text { et al. (33) }\end{array}$ & $\begin{array}{l}41 \text { ACS } \\
\text { patients }\end{array}$ & $\begin{array}{l}50 / 100 \mathrm{mg} \\
\text { sitagliptin vs. diet } \\
\text { therapy }\end{array}$ & $\begin{array}{l}\text { Percent change in } \\
\text { lipid volume }\end{array}$ & $\begin{array}{l}\text { At } 6 \text {-month follow-up, sitagliptin was associated with a greater } \\
\text { reduction of lipid volume }(-7.1 \% \pm 21.5 \% \text { vs. } 15.6 \% \pm 41.8 \%, P=0.03)\end{array}$ \\
\hline $\begin{array}{l}\text { Nozue } \\
\text { et al. (34) }\end{array}$ & $\begin{array}{l}26 \text { CAD } \\
\text { patients }\end{array}$ & $\begin{array}{l}\text { Sitagliptin vs. diet } \\
\text { therapy }\end{array}$ & $\begin{array}{l}\text { Change in IB-IVUS } \\
\text { derived plaque } \\
\text { components }\end{array}$ & $\begin{array}{l}\text { On serial IB-IVUS analysis, a significant decrease in the lipid plaque } \\
\text { volume was observed in subjects receiving sitagliptin (sitagliptin: } \\
\text { from } 200.1 \pm 116.2 \text { to } 179.8 \pm 121.0 \mathrm{~mm}^{3}, \mathrm{P}=0.02 \text {, diet therapy: from } \\
298.3 \pm 363.0 \text { to } 256.6 \pm 386.1 \mathrm{~mm}^{3}, \mathrm{P}=0.1 \text { ) }\end{array}$ \\
\hline
\end{tabular}

ACS, acute coronary syndrome; CAD, coronary artery disease; EPA, Eicosapentaenoic acid; IB-IVUS, integrated backscatter intravascular ultrasound.

with diffuse borders. A sensitivity and specificity for fibrous plaque is ranging from $71 \%$ to $79 \%$ and $97 \%$ to $98 \%$. Those for fibrocalcific plaques and lipid-rich plaques was from $95 \%$ to $96 \%$ and $97 \%$, and $90 \%$ to $94 \%$ and $90 \%$ to $92 \%$, respectively. The interobserver and intraobserver reliabilities of OCT assessment were high (kappa values of 0.88 and 0.91 , respectively). Another ex vivo validation showed an excellent correlation between fibrous cap thickness on OCT and histology ( $r=0.90)$ at 35 lipid-rich plaques of 102 coronary segments in 38 human cadavers (41).

\section{The ability of OCT imaging for future cardiovascular events (Tables 4,5)}

Xing et al. investigated the association of lipid-rich plaques at non-culprit lesions with MACE (= cardiac death, acute myocardial infarction, and ischemia-driven revascularization) (48). This analysis included 1,474 patients with CAD who received OCT imaging during PCI. Study subjects were prospectively enrolled at 20 cites across 6 countries. OCT derived lipid-rich plaque was identified 
Table 4 Clinical studies with OCT imaging — prediction of future cardiovascular events

\begin{tabular}{|c|c|c|c|c|}
\hline Authors & Sites & Population & OCT-derived measure & Findings \\
\hline $\begin{array}{l}\text { Prati } \\
\text { et al. } \\
(43)\end{array}$ & 11 sites & $\begin{array}{l}1,003 \text { patients } \\
\text { with suspected } \\
\text { CAD }\end{array}$ & $\begin{array}{l}\text { Lipid arc }>180^{\circ} \text {, fibrous } \\
\text { cap thickness }<75 \mu \mathrm{m} \text {, } \\
\text { macrophages minimum } \\
\text { lumen area }<3.5 \mathrm{~mm}^{2}\end{array}$ & $\begin{array}{l}\text { Lipid arc }>180^{\circ}(\mathrm{HR}=2.4,95 \% \mathrm{Cl}: 1.2-4.8, \mathrm{P}=0.017) \text {, fibrous cap } \\
\text { thickness }<75 \mu \mathrm{m}(\mathrm{HR}=4.7,95 \% \mathrm{Cl}: 2.4-9.0, \mathrm{P}<0.001) \text {, macrophage } \\
(\mathrm{HR}=2.7,95 \% \mathrm{Cl}: 1.2-6.1, \mathrm{P}=0.027) \text { and minimum lumen area } \\
\left.<3.5 \mathrm{~mm}^{2} \text { ( } \mathrm{HR}=2.1,95 \% \mathrm{Cl}: 1.1-4.0, \mathrm{P}=0.032\right) \text {, predicted the } \\
\text { occurrence of cardiac events (= cardiac death and target segment } \\
\text { myocardial infarction) }\end{array}$ \\
\hline
\end{tabular}

$\mathrm{AMI}$, acute myocardial infarction; CAD, coronary artery disease; $\mathrm{Cl}$, confidence interval; HR, hazard ratio; OCT, optical coherence tomography; $\mathrm{PCl}$, percutaneous coronary intervention.

Table 5 Clinical studies with OCT imaging-evaluation of drug efficacy

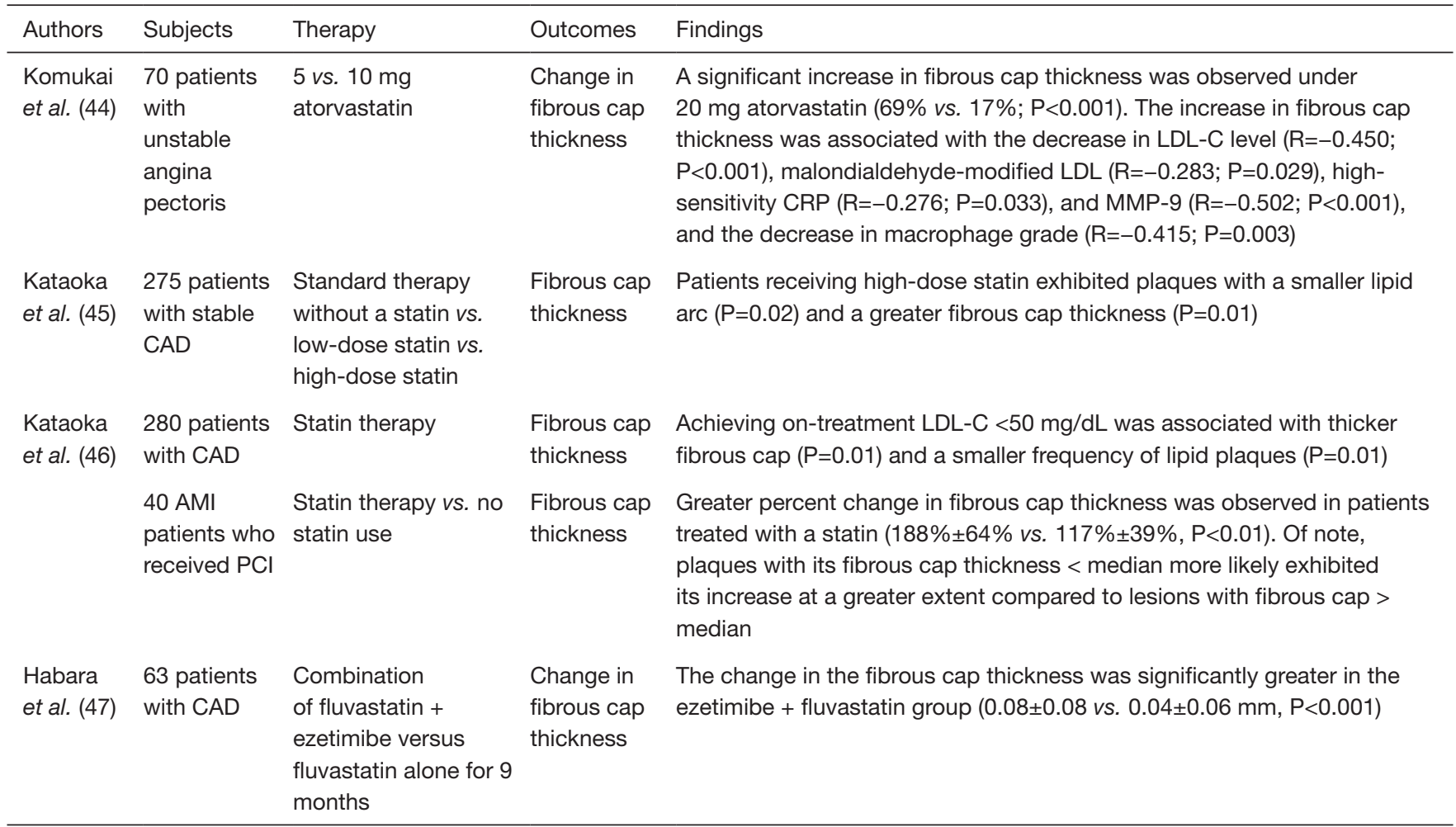

AMI, acute myocardial infarction; CAD, coronary artery disease; $\mathrm{Cl}$, confidence interval; $\mathrm{HR}$, hazard ratio; OCT, optical coherence tomography; $\mathrm{PCl}$, percutaneous coronary intervention. 
in $33.6 \%$ of study subjects. During the follow-up period (median $=2$ years), the presence of lipid-rich plaque was associated with an increased risk of non-culprit lesion related MACE (7.2\% vs. $2.6 \%, \mathrm{P}=0.033)$. On multivariate analysis, independent predictors of non-culprit lesion related MACE included lipid-rich plaque (risk ratio $=2.061$, 95\% CI: $1.050-4.044, \mathrm{P}=0.036$ ), ACS (risk ratio $=2.538$, 95\% CI: $1.246-5.173, \mathrm{P}=0.010)$ and interruption of statin use $>1$ year (risk ratio $=4.517,95 \%$ CI: $1.923-10.610$, $\mathrm{P}=0.001)$. Further OCT analysis elucidated that lipid-rich plaque associated with non-culprit lesion related MACE was more likely to exhibit longer lipid lengths $(9.9 \pm 3.6 \mathrm{vs}$. 7.9 $\pm 4.6, \mathrm{P}<0.001)$, wider maximal lipid arcs $(240.9 \pm 78.4$ vs. $205.1 \pm 69.3, \mathrm{P}=0.023)$ and smaller minimum lumen areas $(3.71 \pm 2.18$ vs. $5.22 \pm 2.87, \mathrm{P}=0.003)$ compared to that without any events.

The CLIMA (Relationship between coronary pLaque morphology of the left anterIor descending artery and longterM clinicAl outcome) study is a prospective observational, multi-center registry (42). This study analyzed 1,776 lipid plaques at proximal segment of left anterior descending artery in 1,003 patients. OCT-derived plaque features associated with cardiac events (= cardiac death and target segment myocardial infarction) included minimum lumen area $<3.5 \mathrm{~mm}^{2}$ ( $\mathrm{HR}=2.1,95 \%$ CI: $1.1-4.0$, $\mathrm{P}=0.032)$, fibrous cap thickness $<75 \mu \mathrm{m}(\mathrm{HR}=4.7,95 \%$ CI: $2.4-9.0, \mathrm{P}<0.001)$, lipid arc $>180^{\circ}(\mathrm{HR}=2.4,95 \%$ CI: $1.2-4.8, \mathrm{P}=0.017)$ and macrophage $(\mathrm{HR}=2.7,95 \% \mathrm{CI}$ : 1.2-6.1, $\mathrm{P}=0.027)$. Of note, lesions containing all of these plaque features exhibited the largest risk of cardiac events ( $\mathrm{HR}=7.54,95 \% \mathrm{CI}: 3.1-18.6, \mathrm{P}<0.001)$. The representative case is shown as Figure 1 (43).

\section{Drug efficacy assessment study with OCT imaging (Table 3)}

The EASY-FIT (Effect of Atorvastatin therapy on fibrous cap thickness in coronary atherosclerotic plaque assessed by OCT) trial is a prospective randomized single-center study which investigated and compared the efficacy of 20 and $5 \mathrm{mg}$ atorvastatin on plaque microstructures in 70 patients with unstable angina pectoris (49). A lower level of on-treatment LDL-C was achieved in subjects taking $20 \mathrm{mg}$ atorvastatin compared to those with $5 \mathrm{mg}$ one. In addition, fibrous cap thickness significantly increased under the use of $20 \mathrm{mg}$ atorvastatin $(69 \%$ vs. $17 \%, \mathrm{P}<0.001)$. Interestingly in particular, an increase in fibrous cap thickness was correlated to a decrease in LDL-C level $(\mathrm{R}=-0.450, \mathrm{P}<0.001)$.

One retrospective study analyzed OCT plaque features in 275 patients with CAD receiving PCI (44). Compared to subjects who did not receive a statin, statin use with a greater intensity was associated with thicker fibrous cap $(\mathrm{P}=0.01)$ and a lower frequency of TCFA $(\mathrm{P}<0.001)$ and vaso vasorum $(\mathrm{P}=0.01)$. Another retrospective analysis investigated the association of on-treatment LDL-C level with plaque microstructures (45). Achieving a lower ontreatment LDL-C level was inversely associated with thickness of fibrous cap. Moreover, in patients with ontreatment LDL-C $<50 \mathrm{mg} / \mathrm{dL}$, the prevalence of TCFA was lowest compared to others. These favourable efficacies of lowering LDL-C with a statin was consistently observed in various subsets except diabetic patients.

Habara et al. compared the efficacy of ezetimibe + fluvastatin $v s$. fluvastatin alone on plaque microstructures in 63 patients with CAD (46). Predictably, combination therapy was associated with a greater reduction of LDL-C level at 9 months $(-34.0 \pm 32.0$ vs. $-8.3 \pm 17.4 \mathrm{mg} / \mathrm{dL}$, $\mathrm{P}<0.001)$. OCT imaging analysis demonstrated a greater increase in fibrous cap thickness in the ezetimibe + fluvastatin group $(0.08 \pm 0.08$ vs. $0.04 \pm 0.06 \mathrm{~mm}, \mathrm{P}<0.001)$. This result supports favourable anti-atherosclerotic efficacies of ezetimibe, which could account for better cardiovascular outcomes in subjects receiving both ezetimibe and statin in recent clinical trial (47).

\section{Consideration of limitation of OCT imaging}

Since penetration depth of OCT imaging is only 2 to $3 \mathrm{~mm}$, it is not suitable for evaluation of plaques in large arteries (coronary diameter $>4 \mathrm{~mm}$ ), and it can not measure plaque area and volume. It is necessary to continuously infuse contrast medium or low-molecular-weight dextran during its pullback because red blood cell causes signal attenuation. Therefore, this modality is not appropriate for imaging of aorto-ostial stenosis. Since the new frequency-domain OCT system enables to acquire 100 frames/sec with its pullback speed up to $20 \mathrm{~mm} /$ sec, it need only bolus injection of contrast medium or lowmolecular-weight dextran for imaging (50).

Another limitation is that interpretation of images is quite subjective. In particular, evaluation of lipid plaque component is always challenging. Furthermore, measurement of fibrous cap thickness varies in each individual. One study investigated the way to improve reproducibility of lipid arc and fibrous cap measurements (51). Intraclass correlation coefficients of these measures between two independent physicians were 0.76 and 0.56 , respectively. After discussion, consensus and developing 

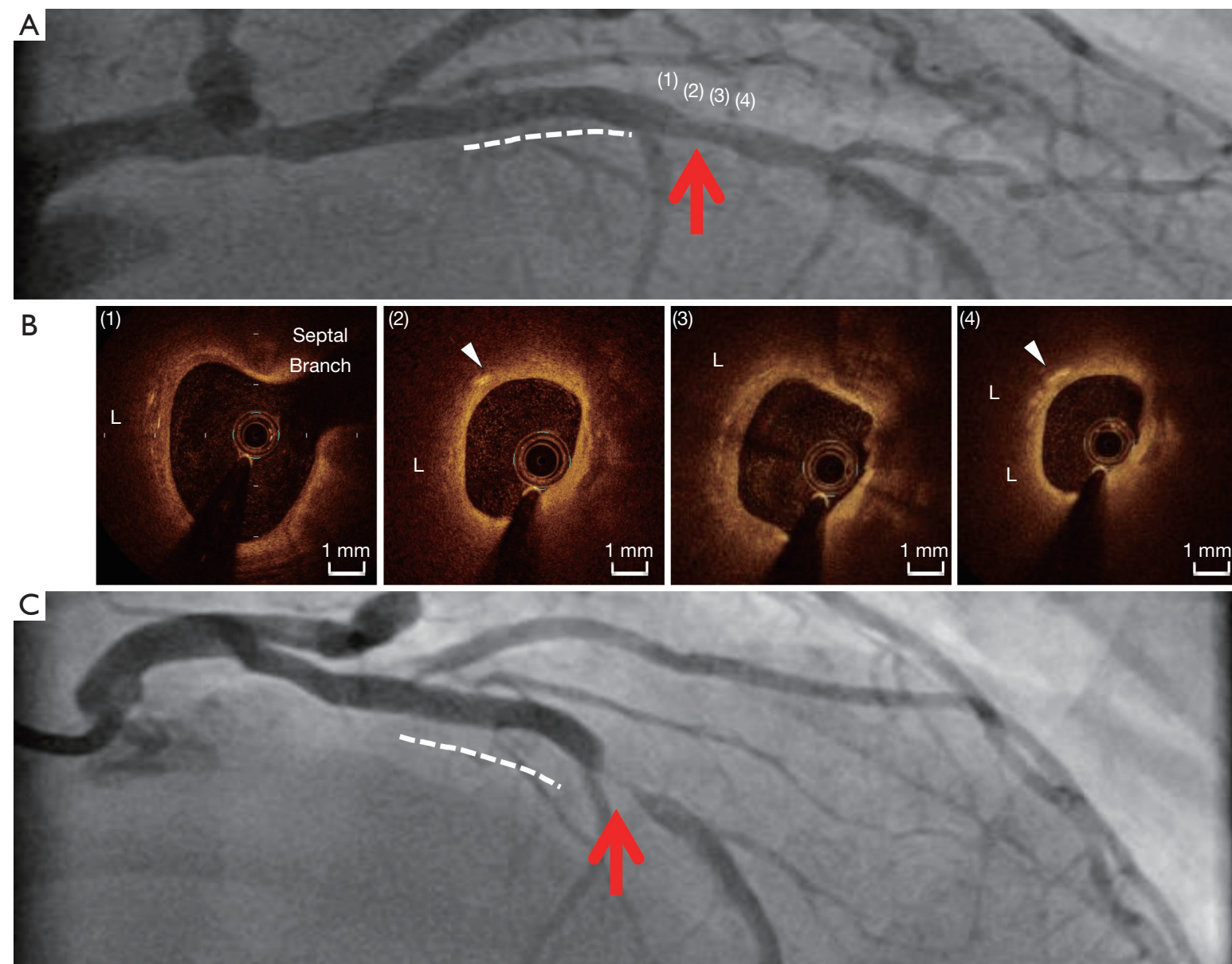

Figure 1 The recurrence of ACS due to progression of lipid-rich plaque containing cholesterol crystal (28). (A) A 60-year-old man with ST-segment elevation myocardial infarction received DES implantation at the middle segment of LAD (dotted line). There was a mild residual stenosis in LAD (red arrow). [1-4] correspond to OCT images in (B). (B) OCT imaging visualized the presence of lipid-rich plaque (L) harbouring cholesterol crystal (white triangle). (C) One year later, non-ST-segment elevation myocardial infarction occurred due to the progression of lipid-rich lesions with cholesterol crystal despite statin therapy (red arrow). ACS, acute coronary syndrome; DES, drugeluting stent; LAD, left anterior descending artery; OCT, optical coherence tomography.

algorithms in physicians, reproducibility of measurements was improved, reflected by intraclass correlation coefficients at 0.82 and 0.88 , respectively. This study indicates that mutual discussion and consensus are mandatory for accurate and reproducible OCT analysis. In the future, novel technologies such as machine learning and/or artificial intelligence could be a solution to improve OCT measurement.

Jia et al. established the criteria of OCT-defined plaque erosion (52). OCT-defined plaque erosion is defined and categorized according to the absence of fibrous cap disruption and the presence of thrombus. This OCT- based diagnostic approach of plaque erosion is attractive. However, correct diagnosis of plaque erosion in vivo by using OCT is not easy in the clinical settings. Given that the presence of luminal thrombus hampers the penetration of light into the underlying plaque, it is difficult to assess features of plaques behind attached thrombus. We experienced one ACS case diagnosed as plaque erosion according to OCT-based criteria (53) (Figure 2). However, considering clinical characteristics including the presence of atrial fibrillation enables to diagnosis as coronary embolism but not plaque erosion. As such, meticulous evaluation of plaques suspected with its erosion is required. 

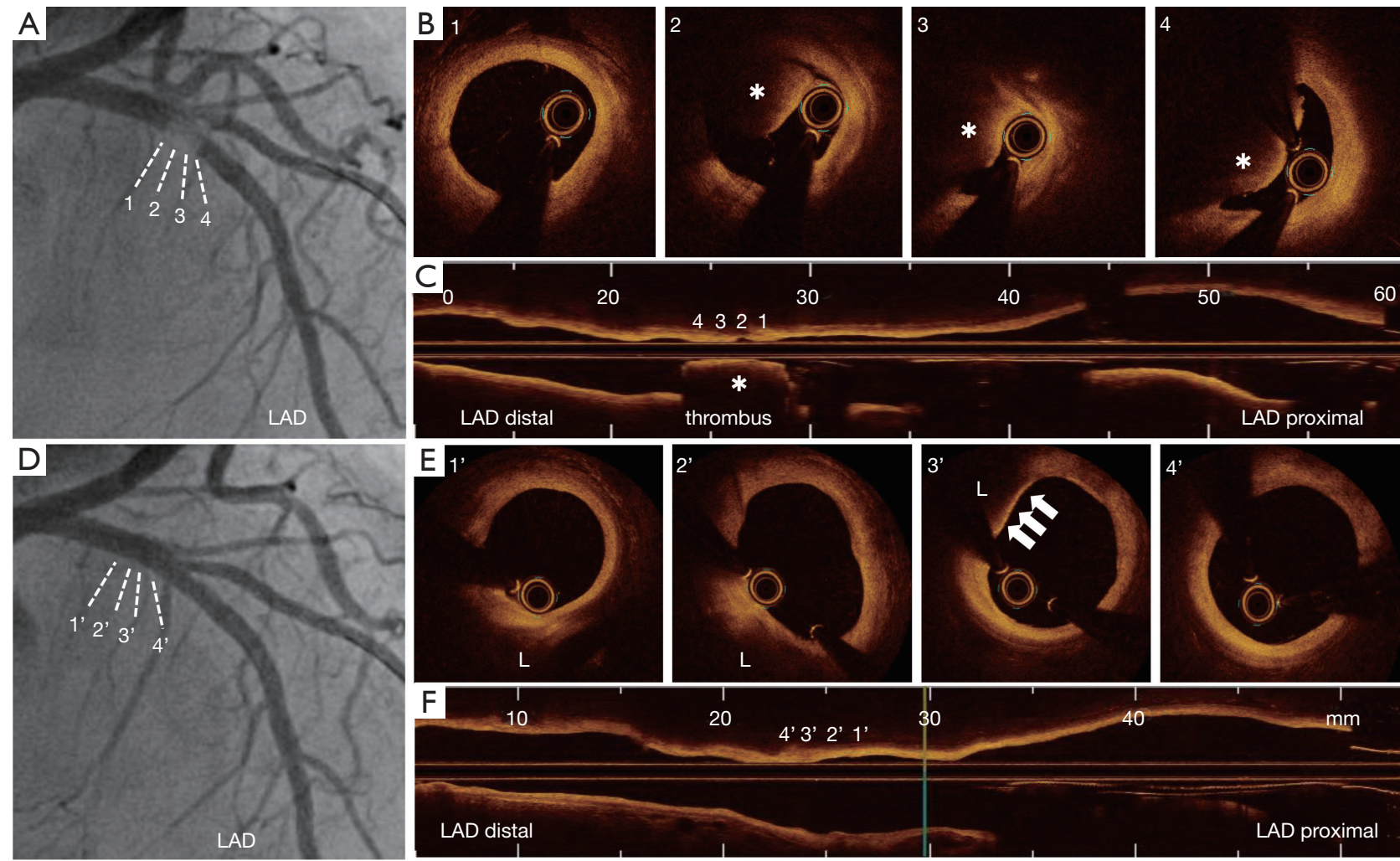

20

$\mathrm{L}=$ Iipid, white arrows $=$ macrophage

Figure 2 Limitation of OCT imaging for correct diagnosis of plaque erosion (35). (A) A 93-year-old woman was hospitalized due to anterior STEMI. Coronary angiography identified TIMI grade II flow with severe stenosis within LAD. [1-4] correspond to OCT images in (B and $\mathrm{C})$. (B,C) The surface of culprit lesion was invisible due to its overlying thrombus (*) [2-4]. (D) After retrieving red thrombus with thrombectomy catheter, TIMI grade III flow was achieved without any residual stenosis. 1'-4' correspond to OCT images in (E and F). (E) On OCT imaging after thrombectomy, an intact fibrous cap and signal attenuation were observed [1'-4']. This lesion was accompanied by adjacent focal signal-rich region (3': white arrows), suggesting the small lipidic plaque with superficial macrophages. IVUS, intravascular ultrasound; LAD, left anterior descending artery; OCT, optical coherence tomography; STEMI, ST-segment elevation myocardial infarction; TIMI, thrombolysis in myocardial infarction.

\section{NIRS imaging}

\section{Quantitative assessment of lipid atheroma on NIRS}

NIRS imaging uses the technique of specifically identifying lipidic plaque components within vessel wall according to a spectroscopic algorithm $(54,55)$. NIRS has the ability to identify cholesterol within atherosclerotic plaques based on specific spectra of cholesterol. According to an algorithm constructed with pathohistological data, this modality shows the probability whether the imaged atherosclerotic lesions harbour a lipid core plaque. The probability of lipid core plaque is shown as the following four different colors; red (probability $<0.57)$, orange $(0.57 \leq$ probability $<0.84), \tan (0.84 \leq$ probability $<0.98)$ and yellow (probability $\geq 0.98$ ). The lipid core burden index (LCBI) is calculated by the proportion of pixels with the probability of a lipid plaque above 0.6 per million (\%o, multiplied by 1,000 ). NIRS provides two measures which include mean LCBI and maximum LCBI at $4 \mathrm{~mm}$ segment $\left(\mathrm{LCBI}_{\max 4 \mathrm{~mm}}\right)$. Mean LCBI is the fraction of pixels above probability of 0.6 in a region of interest. $\mathrm{LCBI}_{\max 4 \mathrm{~mm}}$ exhibits the maximum LCBI at $4-\mathrm{mm}$ segment within a region of interest. 


\section{Validation of chemogram on NIRS imaging}

The ability of NIRS imaging to reveal plaque compositions associated with its instability has been analyzed by using 199 samples of 5 human aortic specimens (56). In this analysis, 35 of 39 lesions with lipid pools and 56 of 60 lesions without lipid pools were identified by NIRS imaging (sensitivity $=90 \%$, specificity $=93 \%)$. This modality detected other unstable plaque features including thin fibrous cap and the presence of inflammatory cells (thin fibrous caps: sensitivity $=77 \%$, specificity $=93 \%$, inflammatory cells: sensitivity $=84 \%$, specificity $=91 \%$ ) (56). Gardner et al . performed ex vivo validation study using human coronary specimens (57). This study analyzed 212 coronary segments of 84 autopsy hearts by NIRS imaging and histopathological evaluation of sections taken at 2-mm intervals. The algorithm established from the first 33 hearts was effective to identify lipid core plaques with a receiver operating characteristics curve area of 0.80 (95\% CI: 0.76-0.85). Additionally, a higher LCBI corresponded to the presence of any fibroatheroma with an area under the curve of 0.86 (95\% CI: 0.81-0.91). Another validation study of the NIRS algorithm is the SPECTACL (SPECTroscopic Assessment of Coronary Lipid) study with 106 patients with CAD (58). The investigators compared acquired spectra with NIRS signal in autopsy coronary specimens. On multivariate statistics, spectral similarity was observed in 40 of 48 scans ( $83 \%$ success rate, $95 \%$ CI: $70-93 \%)$. Additionally, $58 \%$ of 60 scans identified the presence of lipid core plaques.

Recently, the relationship of NIRS/IVUS derived measures with coronary fibroatheroma was analyzed in 116 coronary artery specimens of 51 autopsied hearts (59). LCBI, IVUS derived plaque volume and histological grading according to modified American Heart Association criteria were investigated at each $2-\mathrm{mm}$ block sections $(\mathrm{n}=2,070)$ and lesions $(\mathrm{n}=102)$. On a block-level analysis, histological complexity significantly increased in association with the extent of plaque burden and LCBI $(\mathrm{P}<0.001$ for trend for plaque burden and LCBI). Furthermore, coronary fibroatheroma exhibited the highest remodeling index compared to other types of plaques $(\mathrm{P}=0.001$ for trend). Receiver-operating curve analysis elucidated plaque burden, LCBI and remodeling index as significant features associated with the presence of fibroatheroma (c-indices: $0.675,0.712$ and 0.672 , respectively). Collectively, these validation studies suggest that NIRS imaging is feasible with reasonable sensitivity and specificity to assess the extent of lipidic materials in vivo.

\section{The ability of NIRS imaging for future cardiovascular events}

Several single-center studies have been conducted to investigate the prognostic value of LCBI from 2014 to 2017 (60-63) (Tables 6,7). Oemrawsingh et al. analyzed 203 CAD patients in which their non-culprit vessel was imaged by NIRS (Tables 4,5) (67). Subjects with LCBI above median value of LCBI $(=43.0)$ was associated with an increased risk of MACE (= all-cause mortality, nonfatal ACS, stroke and unplanned coronary revascularization) compared to those with LCBI below its median value $(16.7 \%$ vs. $4.0 \%, \log$-rank, $\mathrm{P}=0.003)$. Even after adjusting baseline clinical characteristics (age, sex, hypercholesterolemia, diabetes, hypertension, history of myocardial infarction, peripheral artery disease and a history of PCI), there was a 4.04 (95\% CI: 1.33-12.29, $\mathrm{P}=0.01$ ) greater likelihood of experiencing MACE during one-year observational period. Another analysis from the Spectrum NIRS-IVUS Registry included 121 CAD patients monitored by NIRS imaging (Tables 4,5) (60). Cox regression analysis showed $\operatorname{maxLCBI}_{4 \mathrm{~mm}} \geq 400$ at non-culprit segment as one-year occurrence of MACE (HR =10.2, 95\% CI: 3.4-30.6, $\mathrm{P}<0.001)$. Four-year follow-up data has been presented by Schuurman et al. (61). They analyzed NIRS data at nonculprit vessel of 275 patients with CAD. During a median follow-up of 4.1 years, there was a statistically significant continuous relationship between higher $\mathrm{LCBI}_{\max 4 \mathrm{~mm}}$ values and a higher risk of MACEs. Multivariate analysis continued to demonstrate the association of $\mathrm{LCBI}_{\max 4 \mathrm{~mm}}$ with MACE (HR =1.19 per 100 units increase in LCBI, 95\% CI: $1.07-1.32, \mathrm{P}=0.001)$. While these findings indicate the potential of NIRS to predict future events, there are some limitation which includes small size of study population and single center study. To overcome these limitations of published studies, the LRP (Lipid Rich Plaque) Study has been recently conducted (Tables 6,7) (63). The LRP study is a prospective cohort study which enrolled 1,563 subjects with CAD. NIRS imaging was conducted at non-stented segment with its length above $50 \mathrm{~mm}$. This imaging procedure was performed from at least two major coronary arteries. Patient-based analysis showed that subjects with maxLCBI ${ }_{4 \mathrm{~mm}} \geq 400$ predicted non-culprit lesion-related MACE (adjusted HR $=1.89$, 95\% CI: 1.26 $2.83, \mathrm{P}=0.0021)$. Segment-based analysis also revealed that segment exhibiting maxLCBI ${ }_{4 \mathrm{~mm}} \geq 400$ associated with a greater frequency of MACE (adjusted HR $=3.39,95 \%$ CI: $1 \cdot 85-6.20, \mathrm{P}<0.0001)$. Figure 3 illustrates a representative 
Table 6 Clinical studies with NIRS imaging — prediction of future cardiovascular events

\begin{tabular}{|c|c|c|c|c|}
\hline Authors & Cites & Population & NIRS-derived measure & Findings \\
\hline $\begin{array}{l}\text { Madder et al. } \\
(61)\end{array}$ & $\begin{array}{l}\text { Single } \\
\text { center }\end{array}$ & $\begin{array}{l}121 \text { patients } \\
\text { with suspected } \\
\text { CAD (ACS }=103 \\
\text { stable } C A D=18)\end{array}$ & $\begin{array}{l}\text { Max4 mmLCBI at non- } \\
\text { stented segment }\end{array}$ & $\begin{array}{l}\text { Max4 mmLCBI }>400 \text { was associated with MACCE (all-cause } \\
\text { mortality, non-fatal ACS, acute cerebrovascular events) during } \\
\text { follow-up: } \mathrm{HR}=10.2,95 \% \mathrm{Cl}: 3.4-30.6, \mathrm{P}<0.001\end{array}$ \\
\hline $\begin{array}{l}\text { Schuurman } \\
\text { et al. (62) }\end{array}$ & $\begin{array}{l}\text { Single } \\
\text { center }\end{array}$ & $\begin{array}{l}275 \text { patients with } \\
\text { CAD (ACS }=117 \\
\text { stable CAD } \\
=158)\end{array}$ & $\begin{array}{l}\text { Max4 mmLCBI at non- } \\
\text { culprit vessel (at least } \\
40 \mathrm{~mm} \text { in length, \% } \\
\text { diameter stenosis <50\%) }\end{array}$ & $\begin{array}{l}\text { Each } 100 \text { units increase of Max } 4 \mathrm{mmLCBI} \text { was associated with } \\
\text { a } 19 \% \text { increase in MACE (= all-cause death, non-fatal ACS, } \\
\text { unplanned revascularization): } \mathrm{HR}=1.19,95 \% \mathrm{Cl}: 1.07-1.32 \text {, } \\
\mathrm{P}=0.001\end{array}$ \\
\hline $\begin{array}{l}\text { Waksman } \\
\text { et al. (64) }\end{array}$ & $\begin{array}{l}44 \text { cites } \\
\text { from } 6 \\
\text { countries }\end{array}$ & $\begin{array}{l}1,563 \text { patients } \\
\text { with CAD (ACS } \\
=974, \text { stable } \\
\text { CAD }=589)\end{array}$ & $\begin{array}{l}\text { Max4 mmLCBI at non- } \\
\text { stented segment from at } \\
\text { least two major coronary } \\
\text { arteries ( }>50 \mathrm{~mm} \text { in } \\
\text { length) }\end{array}$ & $\begin{array}{l}\text { Patient-based analysis: Max } 4 \mathrm{mmLCBI}>400 \text { was associated with } \\
\text { non-culprit lesion related MACE ( }=\text { cardiac death, cardiac arrest, } \\
\text { non-fatal MI, ACS, revascularization): adjusted } \mathrm{HR}=1.89,95 \% \\
\mathrm{Cl}: 1.26-2.83, \mathrm{P}=0.021 \text {. Segment-based analysis: Max } 4 \mathrm{mmLCBI} \\
>400 \text { was associated with non-culprit lesion related MACE: } \\
\text { adjusted } \mathrm{HR}=3.39,95 \% \mathrm{Cl}: 1.85-6.20, \mathrm{P}<0.0001\end{array}$ \\
\hline
\end{tabular}

ACS, acute coronary syndrome; CAD, coronary artery disease; CI, confidence interval; HR, hazard ratio; MACE, major adverse cardiovascular events; NIRS, near-infrared spectroscopy; LCBI, lipid core burden index.

Table 7 Clinical studies with NIRS imaging_evaluation of drug efficacy

\begin{tabular}{|c|c|c|c|c|}
\hline Authors & Population & Drug & Outcome & Findings \\
\hline $\begin{array}{l}\text { Dohi } \\
\text { et al. (66) }\end{array}$ & $\begin{array}{l}87 \text { patients } \\
\text { with } \\
\text { multivessel } \\
\text { CAD }\end{array}$ & $\begin{array}{l}\text { Standard } v \text { s. } \\
\text { intensive statin } \\
\text { ( } 20 \text { mg rosuvastatin) }\end{array}$ & $\begin{array}{l}\text { Max4 } \mathrm{mmLCBI} \text { at lesions } \\
\text { with its percent diameter } \\
\text { stenosis }>70 \% \text { and } \\
\text { fractional flow reserve }<0.8\end{array}$ & $\begin{array}{l}\text { Max } 4 \mathrm{mmLCBI} \text { did not change at lesions with } \mathrm{Max} 4 \mathrm{mmLCBI} \text { under } \\
\text { the use of } 20 \mathrm{mg} \text { rosuvastatin. By contrast, } L C B \mathrm{I}_{\max 4 \mathrm{~mm}} \text { significantly } \\
\text { reduced at lesions with } \mathrm{LCBI}_{\max 4 \mathrm{~mm}} \geq 500 \text { under } 20 \mathrm{mg} \text { rosuvastatin } \\
\text { use (median: } 703 \text { at baseline, } 399 \text { at } 7 \text { weeks, } P=0.004 \text { ) }\end{array}$ \\
\hline
\end{tabular}

ACS, acute coronary syndrome; CAD, coronary artery disease; CI, confidence interval; HR, hazard ratio; MACE, major adverse cardiovascular events; NIRS, near-infrared spectroscopy; LCBI, lipid core burden index.

case which showed the occurrence of ACS at lesion containing maxLCBI ${ }_{4 \mathrm{~mm}} \geq 400$. NIRS imaging could be an applicable tool in the clinical settings for risk stratification in patients with CAD.

\section{Drug efficacy assessment study with NIRS imaging}

The YELLOW (Reduction in Yellow Plaque by Intensive
Lipid Lowering Therapy) trial is the first study to use NIRS for the evaluation of drug efficacy in patients with CAD (64) (Tables 6,7). This trial was a prospective, randomized study which enrolled 86 patients with multivessel obstructive CAD. Study subjects were randomized to standard or intensive statin therapy. The target segment for imaging was the lesion with its percent diameter stenosis $\geq 70 \%$ and fractional flow reserve $<0.8$. After 7 weeks of the therapy, 


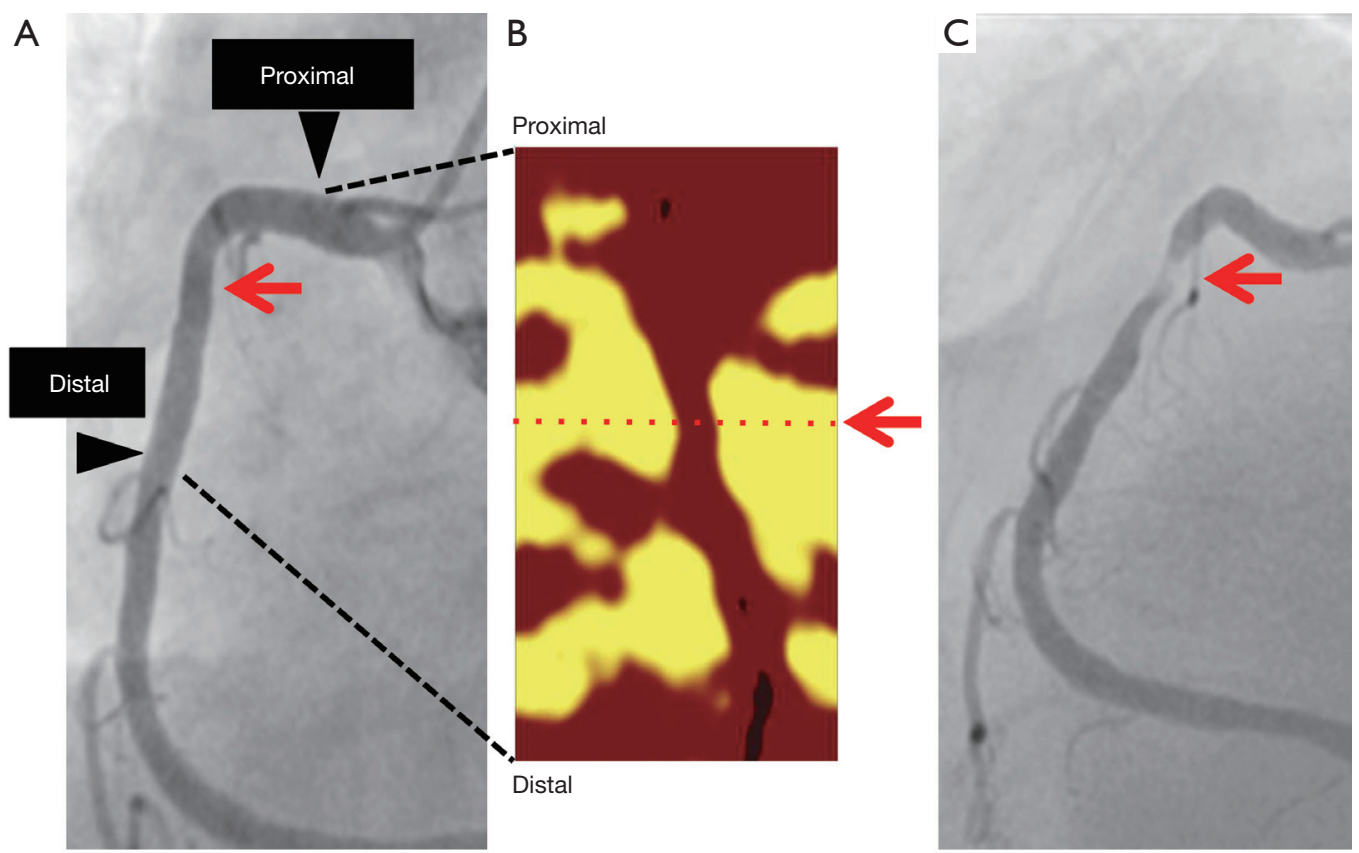

Figure 3 Progression of non-obstructive lesion harbouring high Max4 mmLCBI. (A) 70-year old gentleman received diagnostic coronary angiography due to suspected anginal chest symptom. There was a mild stenosis at the proximal segment of RCA (red arrow). (B) NIRS imaging identified high Max4 mmLCBI (=882) at the corresponding lesion (red arrow). (C) One year later, ACS occurred due to the progression of the lesion with high Max4 mmLCBI (red arrow). ACS, acute coronary syndrome; LCBI, lipid core burden index; NIRS, near-infrared spectroscopy; RCA, right coronary artery.

greater reduction of LDL-C level was observed in subjects receiving intensive statin therapy (20 $\mathrm{mg}$ rosuvastatin) (58.4 \pm 26.3 vs. $81.9 \pm 27.9 \mathrm{mg} / \mathrm{dL}, \mathrm{P}<0.001)$. Serial greyscale IVUS imaging showed that coronary atheroma volume at 7 weeks after the therapy did not differ between two groups. However, on NIRS imaging analysis, intensive statin therapy was associated with a significant reduction of LCBI $_{\max 4 \mathrm{~mm}}$ (median percent change: $-32.2 \%$ vs. $-0.6 \%$, $\mathrm{P}=0.02$ ).

Another interesting observation about the association of LCBI with response to intensive statin therapy was reported by a sub-analysis of YELLOW trial (65) (Tables 6,7). This therapeutic regimen did not alter lipid component at coronary atheroma harbouring $\mathrm{LCBI}_{\max 4 \mathrm{~mm}}<500$, whereas a marked reduction of $\mathrm{LCBI}_{\max 4 \mathrm{~mm}}$ was observed at lesions with $\mathrm{LCBI}_{\max 4 \mathrm{~mm}} \geq 500$ under $20 \mathrm{mg}$ rosuvastatin use (median: 703 at baseline, 399 at 7 weeks, $\mathrm{P}=0.004$ ). As such, serial NIRS imaging provides a novel opportunity to elucidate the efficacy of therapies as well as the mechanism behind its efficacy.

\section{Consideration of limitation of NIRS imaging}

Near-infrared light reaches around $3 \mathrm{~mm}$ far from the center of catheter. Therefore, NIRS could provide information of lipidic plaque component at shallow depth. It may be difficult to evaluate lipidic features at deeper area in depth.

Validation study did not evaluate NIRS imaging at lesions with thrombus at its surface. Whether the presence of thrombus affects NIRS signals remains to be determined yet.

\section{Coronary angioscopy}

\section{Validation of coronary angioscopy imaging}

Coronary angioscopy enables to directly visualize color and morphological characteristics of plaque surface in vivo. Validation study has been conducted by comparing with coronary specimens retrieved by atherectomy catheter (66). In this analysis, white colored plaque mainly corresponded 
Table 8 Clinical studies with coronary angioscopy imaging - prediction of future cardiovascular events

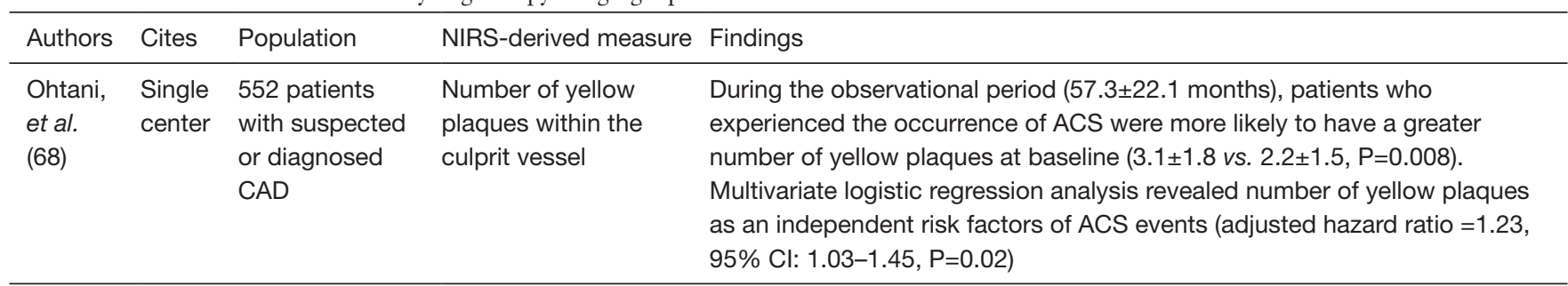

ACS, acute coronary syndrome; CAD, coronary artery disease; $\mathrm{Cl}$, confidence interval.

Table 9 Clinical studies with coronary angioscopy imaging-evaluation of drug efficacy

\begin{tabular}{|c|c|c|c|c|}
\hline Authors & Population & Drug & Outcome & Findings \\
\hline $\begin{array}{l}\text { Kodama, } \\
\text { et al. (70) }\end{array}$ & $\begin{array}{l}46 \text { patients } \\
\text { with CAD }\end{array}$ & $2 \mathrm{mg}$ pitavastatin & $\begin{array}{l}\text { Change in } \\
\text { yellow grade }\end{array}$ & $\begin{array}{l}\text { Following } 52 \text {-week pitavastatin use, yellow grade significantly } \\
\text { decreased (from } 2.9 \pm 0.8 \text { to } 2.6 \pm 0.7, P=0.04 \text { ). }\end{array}$ \\
\hline
\end{tabular}

ACS, acute coronary syndrome; CAD, coronary artery disease; $\mathrm{Cl}$, confidence interval.

to fibrous lesion. Additionally, yellow colored plaque was more likely to associate with atheroma containing necrotic tissue.

\section{The ability of coronary angioscopy imaging for future cardiovascular events (Tables 8,9)}

The association of yellow plaques on coronary angioscopy with future risk of ACS has been reported in 2006 (68). A total of 552 subjects with suspected or diagnosed CAD who received coronary angioscopy were analyzed. During the observational period (57.3 \pm 22.1 months), patients with the number of yellow plaques $\geq 2(9.0 \%$ vs. $4.1 \%, \mathrm{P}=0.02)$ and $\geq 5$ ( $15.6 \%$ vs. $4.1 \%, \mathrm{P}=0.01)$ exhibited a greater likelihood of experiencing ACS compared to those without any yellow plaques.

\section{Drug efficacy assessment study with coronary angioscopy (Tables 8,9)}

Takano et al. compared change in plaque colour between atorvastatin therapy and diet therapy in 31 patients with
CAD (69). During the 12 -month observational period, atorvastatin therapy induced a significant decrease in mean yellow score $(\mathrm{P}=0.002)$. Similar finding was reported by the TOGETHER trial which investigated the efficacy of pitavastatin on yellow plaques (70). In this study, the use of $2 \mathrm{mg}$ pitavastatin for 52 weeks was associated with a reduction of yellow grade $(2.9 \pm 0.8$ to $2.6 \pm 0.7, \mathrm{P}=0.04)$. Ueda et al. used coronary angioscopy to elucidate the efficacy of ezetimibe on yellow plaques (ZIPANGU study: Ezetimibe clinical investigation for the regression of intracoronary plaque evaluated by angioscopy and ultrasound) (71). This study randomized 131 stable CAD patients to atorvastatin + ezetimibe or atorvastatin alone. Serial coronary angioscopy demonstrated that the extent of yellow colour reduction was similar in both groups.

\section{Consideration of limitation of coronary angioscopy imaging}

Since it is required to remove blood for imaging, continuous infusion of low-molecular-weight dextran is continuously infused. Visualized area on coronary angioscopy is limited, 
and therefore, this modality can not visualize all of plaques within vessel wall. Yellow colour assessment is a subjective measure. This limitation suggests that yellow colour grade may be different between each physician.

\section{Comparison of each imaging modality}

As mentioned above, VH-IVUS, IB-UVUS, OCT, NIRS and coronary angioscopy are similar to visualize vulnerable plaque. In addition, it is important to understand the following differences in each modality for better selection and interpretation of images.

\section{Imaging procedure}

OCT and coronary angioscopy requires the continuous infusion of contrast medium or low-molecular-weight dextran for its imaging, whereas others do not. This technical aspect could affect the quality of acquired images.

\section{Measurement of vessel dimensions}

Values of measurement about vessel and lumen diameter is different between VH-IVUS, IB-IVUS and OCT, whereas NIRS and coronary angioscopy does not provide any information of vessel and lumen sizes. In detail, although the measurements of vessel dimensions on OCT is significantly correlated to those on VH-IVUS and IBIVUS, their small differences exist (11-22\%). In particular, the interventionalist has to recognize that lumen area measured by OCT is normally smaller than IVUS-derived one (72).

\section{Visualization of plaque compositions}

VH-IVUS, IB-IVUS, OCT and coronary angioscopy shows a variety of plaque components/structures, whereas NIRS evaluates only the degree of lipidic plaque materials.

\section{Evaluation of TCFA}

One study showed the discrepancy of TCFA between VHIVUS and OCT (73). In this analysis, there were $61 \mathrm{VH}-$ IVUS derived and 36 OCT-derived TCFAs. Of these, only 28 lesions fulfilled both VH-IVUS and OCT based TCFA definition. The remaining 33 VH-IVUS TCFA did not exhibit thin-cap on OCT, and 8 OCT TCFA exhibited less than $10 \%$ of necrotic core areas in contact with the lumen.

\section{Quantitative analysis of plaque composition}

VH-IVUS and IB-IVUS measure the volume of each plaque component. NIRS enables to provide quantitative measurement of lipidic plaque materials. By contrast, the assessment of plaque component, especially lipid plaque on OCT and plaque colour grade on coronary angioscopy are subjective.

\section{Future directions}

While the currently available intravascular imaging modalities provide a variety of anatomical information of coronary atheroma in vivo, recent studies indicate not only anatomical data but also other plaque-related characteristics as another important contributor to plaque vulnerability. For instance, Costopoulos et al. reported the association of plaque structural stress and wall shear stress with plaque vulnerability and progression (74). In this analysis, high plaque structural stress and low wall shear stress were associated with an increased vulnerability and plaque progression, respectively.

Another potential feature of plaques is its biological functionality (75). Intravascular near-infrared fluorescence is a novel imaging approach which uses protease-activated fluorescence agent. Pre-clinical study has shown this imaging technique visualized inflammation within vessel wall of rabbit atherosclerosis model (76). Although further clinical studies are warranted to elucidate the feasibility and safety of intravascular imaging of plaque inflammation, visualization of plaque activity will be also important to predict future cardiovascular risks. In the future, by collecting anatomical as well as biomechanical and functional data of coronary plaques, it may be possible to establish novel therapeutic approach to stabilize vulnerable plaque, thereby leading to the prevention of ACS.

\section{Conclusions}

The accumulating evidence from clinical studies have shown intravascular imaging of vulnerable plaques as a great potential tool for predicting future risk of cardiovascular events and evaluating the efficacy of novel agents. However, it is important to recognize that not only anatomical plaque features but also biomechanical factors as well as functionality of plaques could play important roles in driving plaque instability. In addition, a variety of 
biomarkers reflecting pathophysiology of atherosclerosis may help to assess the degree of vulnerability at coronary lesions. Given that technological advances such as machine learning and/or artificial intelligence are rapidly progressing, these technologies are expected to create sophisticated tool which collects anatomical, biomechanical and functional imaging data of coronary atheroma in conjunction with biomarkers. This novel but ideal approach will be useful in refining the degree of plaque vulnerability, which enables to adopt individualizing therapy for further reduction of future coronary event's risk.

\section{Acknowledgments}

Funding: None.

\section{Footnote}

Provenance and Peer Review: This article was commissioned by the Guest Editor (Dennis T. L. Wong) for the series "Intracoronary Imaging" published in Cardiovascular Diagnosis and Therapy. The article was sent for external peer review organized by the Guest Editor and the editorial office.

Conflicts of Interest: All authors have completed the ICMJE uniform disclosure form (available at http://dx.doi. org/10.21037/cdt-20-238). The series "Intracoronary Imaging" was commissioned by the editorial office without any funding or sponsorship. YK serves as an unpaid editorial board member of Cardiovascular Diagnosis and Therapy from Jul 2019 to Jun 2021. The authors have no other conflicts of interest to declare.

Ethical Statement: The authors are accountable for all aspects of the work in ensuring that questions related to the accuracy or integrity of any part of the work are appropriately investigated and resolved.

Open Access Statement: This is an Open Access article distributed in accordance with the Creative Commons Attribution-NonCommercial-NoDerivs 4.0 International License (CC BY-NC-ND 4.0), which permits the noncommercial replication and distribution of the article with the strict proviso that no changes or edits are made and the original work is properly cited (including links to both the formal publication through the relevant DOI and the license). See: https://creativecommons.org/licenses/by-nc-nd/4.0/.

\section{References}

1. Muller JE, Tofler GH, Stone PH. Circadian variation and triggers of onset of acute cardiovascular disease. Circulation 1989;79:733-43.

2. Virmani R, Kolodgie FD, Burke AP, et al. Lessons from sudden coronary death: a comprehensive morphological classification scheme for atherosclerotic lesions. Arterioscler Thromb Vasc Biol 2000;20:1262-75.

3. Davies MJ, Thomas A. Thrombosis and acute coronaryartery lesions in sudden cardiac ischemic death. $\mathrm{N}$ Engl J Med 1984;310:1137-140.

4. DeWood MA, Spores J, Notske R, et al. Prevalence of total coronary occlusion during the early hours of transmural myocardial infarction. N Engl J Med 1980;303:897-902.

5. Farb A, Burke AP, Tang AL, et al. Coronary plaque erosion without rupture into a lipid core: a frequent cause of coronary thrombosis in sudden coronary death. Circulation 1996;93:1354-63.

6. Burke AP, Farb A, Malcom GT, et al. Coronary risk factors and plaque morphology in men with coronary disease who died suddenly. N Engl J Med 1997;336:1276-82.

7. Glagov S, Weisenberg E, Zarins CK, et al. Compensatory enlargement of human atherosclerotic coronary arteries. N Engl J Med 1987;316:1371-5.

8. Burke AP, Kolodgie FD, Farb A, et al. Healed plaque ruptures and sudden coronary death: evidence that subclinical rupture has a role in plaque progression. Circulation 2001;103:934-40.

9. Mintz GS, Nissen SE, Anderson WD, et al. American College of Cardiology Clinical Expert Consensus Document on Standards for Acquisition, Measurement and Reporting of Intravascular Ultrasound Studies (IVUS). A report of the American College of Cardiology Task Force on Clinical Expert Consensus Documents. J Am Coll Cardiol 2001;37:1478-92.

10. Fujii K, Hao H, Shibuya M, et al. Accuracy of OCT, Grayscale IVUS, and Their Combination for the Diagnosis of Coronary TCFA: An Ex Vivo Validation Study. JACC Cardiovasc Imaging 2015;8:451-60.

11. Nair A, Kuban BD, Tuzcu EM, et al. Coronary plaque classification with intravascular ultrasound radiofrequency data analysis. Circulation 2002;106:2200-6.

12. Nasu K, Tsuchikane E, Katoh O, et al. Accuracy of in vivo coronary plaque morphology assessment: a validation study of in vivo virtual histology compared with in vitro histopathology. J Am Coll Cardiol 2006;47:2405-12.

13. Brown AJ, Obaid DR, Costopoulos C, et al. Direct 
Comparison of Virtual-Histology Intravascular

Ultrasound and Optical Coherence Tomography Imaging

for Identification of Thin-Cap Fibroatheroma. Circ

Cardiovasc Imaging 2015;8:e003487.

14. Stone GW, Maehara A, Lansky AJ, et al; PROSPECT Investigators. A prospective natural-history study of coronary atherosclerosis. N Engl J Med 2011;364:226-35.

15. Calvert PA, Obaid DR, O'Sullivan M, et al. Association between IVUS findings and adverse outcomes in patients with coronary artery disease: the VIVA (VH-IVUS in Vulnerable Atherosclerosis) Study. JACC Cardiovasc Imaging 2011;4:894-901.

16. Cheng JM, Garcia-Garcia HM, de Boer SP, et al. In vivo detection of high-risk coronary plaques by radiofrequency intravascular ultrasound and cardiovascular outcome: results of the ATHEROREMO-IVUS study. Eur Heart J 2014;35:639-47.

17. Nasu K, Tsuchikane E, Katoh O, et al. Effect of fluvastatin on progression of coronary atherosclerotic plaque evaluated by virtual histology intravascular ultrasound. JACC Cardiovasc Interv 2009;2:689-96.

18. Puri R, Libby P, Nissen SE, et al. Long-term effects of maximally intensive statin therapy on changes in coronary atheroma composition: insights from SATURN. Eur Heart J Cardiovasc Imaging 2014;15:380-8.

19. Räber L, Taniwaki M, Zaugg S, et al. IBIS 4 (Integrated Biomarkers and Imaging Study-4) Trial Investigators (NCT00962416). Effect of high-intensity statin therapy on atherosclerosis in non-infarct-related coronary arteries (IBIS-4): a serial intravascular ultrasonography study. Eur Heart J 2015;36:490-500.

20. Kubo T, Maehara A, Mintz GS, et al. The dynamic nature of coronary artery lesion morphology assessed by serial virtual histology intravascular ultrasound tissue characterization. J Am Coll Cardiol 2010;55:1590-7.

21. Nicholls SJ, Ballantyne CM, Barter PJ, et al. Effect of two intensive statin regimens on progression of coronary disease. N Engl J Med 2011;365:2078-87.

22. Thim T, Hagensen MK, Wallace-Bradley D, et al. Unreliable assessment of necrotic core by virtual histology intravascular ultrasound in porcine coronary artery disease. Circ. Cardiovasc. Imaging 2010;3:384-91.

23. Nicholls SJ, Puri R, Anderson T, et al. Effect of Evolocumab on Progression of Coronary Disease in Statin-Treated Patients: The GLAGOV Randomized Clinical Trial. JAMA 2016;316:2373-84.

24. Nicholls SJ, Puri R, Anderson T, et al. Effect of Evolocumab on Coronary Plaque Composition. J Am Coll
Cardiol 2018;72:2012-21.

25. Kawasaki $M$, Takatsu $H$, Noda T,et al. In vivo quantitative tissue characterization of human coronary arterial plaques by use of integrated backscatter intravascular ultrasound and com- parison with angioscopic findings. Circulation 2002;105:2487-92.

26. Okubo M, Kawasaki M, Ishihara Y, et al. Development of integrated backscatter intravascular ultrasound for tissue characterization of coronary plaques. Ultrasound Med Biol 2008;34:655-63.

27. Nakano M, Yahagi K, Yamamoto H, et al. Additive Value of Integrated Backscatter IVUS for Detection of Vulnerable Plaque by Optical Frequency Domain Imaging: An Ex Vivo Autopsy Study of Human Coronary Arteries. JACC Cardiovasc Imaging 2016;9:163-72.

28. Kawasaki M, Sano K, Okubo M, et al. Volumetric Quantitative Analysis of Tissue Characteristics of Coronary Plaques After Statin Therapy Using ThreeDimensional Integrated Backscatter Intravascular Ultrasound. J Am Coll Cardiol 2005;45:1946-53.

29. Hattori K, Ozaki Y, Ismail TF, et al. Impact of Statin Therapy on Plaque Characteristics as Assessed by Serial OCT, Grayscale and Integrated backscatter-IVUS. JACC Cardiovasc Imaging 2012;5:169-77.

30. Otagiri K, Tsutsui H, Kumazaki S, et al. Early Intervention With Rosuvastatin Decreases the Lipid Components of the Plaque in Acute Coronary Syndrome: Analysis Using Integrated Backscatter IVUS (ELAN Study). Circ J 2011;75:633-41.

31. Watanabe T, Ando K, Daidoji H, et al. A Randomized Controlled Trial of Eicosapentaenoic Acid in Patients With Coronary Heart Disease on Statins. J Cardiol 2017;70:537-44.

32. Niki T, Wakatsuki T, Yamaguchi K, et al. Effects of the Addition of Eicosapentaenoic Acid to Strong Statin Therapy on Inflammatory Cytokines and Coronary Plaque Components Assessed by Integrated Backscatter Intravascular Ultrasound. Circ J 2016;80:450-60

33. Kuramitsu S, Miyauchi K, Yokoi H, et al. Effect of Sitagliptin on Plaque Changes in Coronary Artery Following Acute Coronary Syndrome in Diabetic Patients: The ESPECIAL-ACS Study. J Cardiol 2017;69:369-76.

34. Nozue T, Fukui K, Koyama Y, et al. Effects of Sitagliptin on Coronary Atherosclerosis in Patients With Type 2 diabetes-A Serial Integrated Backscatter-Intravascular Ultrasound Study. Am J Cardiovasc Dis 2016;6:153-62.

35. Yamaguchi K, Wakatsuki T, Soeki T, et al. Effects of Telmisartan on Inflammatory Cytokines and Coronary 
Plaque Component as Assessed on Integrated Backscatter Intravascular Ultrasound in Hypertensive Patients. Circ J 2014;78:240-7.

36. Jang IK, Bouma BE, Kang DH, et al. Visualization of coronary atheroscle- rotic plaques in patients using optical coherence tomography: comparison with intravascular ultrasound. J Am Coll Cardiol 2002;39:604-9.

37. Jang IK, Tearney GJ, MacNeill B, et al. In vivo characterization of coronary atherosclerotic plaque by use of optical coherence tomography. Circulation 2005;111:1551-5.

38. Kubo T, Imanishi T, Takarada S, et al. Assessment of culprit lesion morphology in acute myocardial infarction: ability of optical coherence tomography compared with intravascular ultrasound and coronary angioscopy. J Am Coll Cardiol 2007;50:933-9.

39. Kitabata H, Tanaka A, Kubo T, et al. Relation of microchannel structure identified by optical coherence tomography to plaque vulnerability in patients with coronary artery disease. Am J Cardiol 2010;105:1673-8.

40. Yabushita H, Bouma BE, Houser SL, et al. Characterization of human atherosclerosis by optical coherence tomography. Circulation 2002;106:1640-5.

41. Kume T, Akasaka T, Kawamoto T, et al. Measurement of the thickness of the fibrous cap by optical coherence tomography. Am Heart J 2006;152:755.e1-4.

42. Prati F, Romagnoli E, Gatto L, et al. Relationship between coronary plaque morphology of the left anterior descending artery and 12 months clinical outcome: the CLIMA study. Eur Heart J 2020;41:383-91.

43. Sugane H, Kataoka Y, Otsuka F, Yasuda S. Cholesterolcrystalized coronary atheroma as a potential precursor lesion causing acute coronary syndrome: a case report. Eur Heart J Case Rep 2019;3:ytz128.

44. Kataoka Y, Puri R, Hammadah M, et al. Frequencydomain optical coherence tomographic analysis of plaque microstructures at nonculprit narrowings in patients receiving potent statin therapy. Am J Cardiol 2014;114:549-54.

45. Kataoka Y, Hammadah M, Puri R, et al. Plaque microstructures in patients with coronary artery disease who achieved very low low-density lipoprotein cholesterol levels. Atherosclerosis 2015;242:490-5.

46. Habara M, Nasu K, Terashima M, et al. Impact on optical coherence tomographic coronary findings of fluvastatin alone versus fluvastatin + ezetimibe. Am J Cardiol 2014;113:580-7.

47. Cannon CP, Blazing MA, Giugliano RP, et al; IMPROVE-
IT Investigators. Ezetimibe Added to Statin Therapy after Acute Coronary Syndromes. N Engl J Med 2015;372:2387-97.

48. Xing L, Higuma T, Wang Z, et al. Clinical Significance of Lipid-Rich Plaque Detected by Optical Coherence Tomography: A 4-Year Follow-Up Study. J Am Coll Cardiol 2017;69:2502-13.

49. Komukai K, Kubo T, Kitabata H, et al. Effect of atorvastatin therapy on fibrous cap thickness in coronary atherosclerotic plaque as assessed by optical coherence tomography: the EASY-FIT study. J Am Coll Cardiol 2014;64:2207-17.

50. Barlis P, Schmitt JM. Current and future developments in intracoronary optical coherence tomography imaging. EuroIntervention 2009;4:529-33.

51. Kini AS, Vengrenyuk Y, Yoshimura T, et al. Fibrous Cap Thickness by Optical Coherence Tomography In Vivo. J Am Coll Cardiol 2017;69:644-657.

52. Jia H, Abtahian F, Aguirre AD, et al. In vivo diagnosis of plaque erosion and calcified nodule in patients with acute coronary syndrome by intravascular optical coherence tomography. J Am Coll Cardiol 2013;62:1748-58.

53. Kitahara S, Kataoka Y, Otsuka F, et al. Plaque erosion or coronary artery embolism? Findings from clinical presentation, optical coherence tomographic and histopathological analysis in a case with acute coronary syndrome. Int J Cardiovasc Imaging 2019;35:1791-2.

54. Caplan JD, Waxman S, Nesto RW, et al. Near-infrared spectroscopy for the detection of vulnerable coronary artery plaques. J Am Coll Cardiol 2006;47(8 Suppl):C92-6.

55. Kilic ID, Caiazzo G, Fabris E, et al. Near-infrared spectroscopy-intravascular ultrasound: scientific basis and clinical applications. Eur Heart J Cardiovasc Imaging 2015;16:1299-306.

56. Moreno PR, Lodder RA, Purushothaman KR, et al. Detection of lipid pool, thin fibrous cap, and inflammatory cells in human aortic atherosclerotic plaques by nearinfrared spectroscopy. Circulation 2002;105:923-7.

57. Gardner CM, Tan H, Hull EL, et al. Detection of lipid core coronary plaques in autopsy specimens with a novel catheter-based near- infrared spectroscopy system. JACC Cardiovasc Imaging 2008;1:638-48.

58. Waxman S, Dixon SR, L'Allier $P$, et al. In vivo validation of a catheter-based near-infrared spectroscopy system for detection of lipid core coronary plaques: initial results of the SPECTACL study. JACC Cardiovasc Imaging 2009;2:858-68.

59. Puri R, Madder RD, Madden SP, et al. Near-Infrared 
Spectroscopy Enhances Intravascular Ultrasound Assessment of Vulnerable Coronary Plaque: A Combined Pathological and In Vivo Study. Arterioscler Thromb Vasc Biol 2015;35:2423-31.

60. Madder RD, Husaini M, Davis AT, et al. Large lipid-rich coronary plaques detected by near-infrared spectroscopy at non-stented sites in the target artery identify patients likely to experience future major adverse cardiovascular events. Eur Heart J Cardiovasc Imaging 2016;17:393-9.

61. Schuurman AS, Vroegindewey M, Kardys I, et al. Nearinfrared spectroscopy-derived lipid core burden index predicts adverse cardiovascular outcome in patients with coronary artery disease during long-term follow-up. Eur Heart J 2018;39:295-302.

62. Danek BA, Karatasakis A, Karacsonyi J, Alet al. Longterm follow-up after near-infrared spectroscopy coronary imaging: Insights from the lipid cORe plaque association with CLinical events (ORACLE-NIRS) registry. Cardiovasc Revasc Med 2017;18:177-81.

63. Waksman R, Di Mario C, Torguson R, et al; LRP Investigators. Identification of patients and plaques vulnerable to future coronary events with near-infrared spectroscopy intravascular ultrasound imaging: a prospective, cohort study. Lancet 2019;394:1629-37.

64. Kini AS, Baber U, Kovacic JC, et al. Changes in plaque lipid content after short-term intensive versus standard statin therapy: the YELLOW trial (reduction in yellow plaque by aggressive lipid-lowering therapy). J Am Coll Cardiol 2013;62:21-9.

65. Dohi T, Maehara A, Moreno PR, et al. The relationship among extent of lipid-rich plaque, lesion characteristics, and plaque progression/regression in patients with coronary artery disease: a serial near-infrared spectroscopy and intravascular ultrasound study. Eur Heart J Cardiovasc Imaging 2015;16:81-7.

66. Thieme T, Wernecke KD, Meyer R, et al. Angioscopic evaluation of atherosclerotic plaques: validation by histomorphologic analysis and association with stable and unstable coronary syndrome. J Am Coll Cardiol 1996;28:1-6.

67. Oemrawsingh RM, Cheng JM, García-García HM, et al. Near-infrared spectroscopy predicts cardiovascular outcome in patients with coronary artery disease. J Am Coll Cardiol 2014;64:2510-8.

68. Ohtani T, Ueda Y, Mizote I, et al. Number of yellow plaques detected in a coronary artery is associated with future risk of acute coronary syndrome: detection of vulnerable patients by angioscopy. J Am Coll Cardiol 2006;47:2194-200.

69. Takano M, Mizuno K, Yokoyama S, et al. Changes in coronary plaque color and morphology by lipid-lowering therapy with atorvastatin: serial evaluation by coronary angioscopy. J Am Coll Cardiol 2003;42:680-6.

70. Kodama K, Komatsu S, Ueda Y, et al. Stabilization and regression of coronary plaques treated with pitavastatin proven by angioscopy and intravascular ultrasound--the TOGETHAR trial. Circ J 2010;74:1922-8.

71. Ueda Y, Hiro T, Hirayama A, et al. Effect of Ezetimibe on Stabilization and Regression of Intracoronary Plaque The ZIPANGU Study. Circ J 2017;81:1611-9.

72. Okamura T, Onuma Y, Garcia-Garcia HM, et al. Firstin-man evaluation of intravascular optical frequency domain imaging (OFDI) of Terumo: A comparison with intravascular ultrasound and quantitative coronary angiography. EuroIntervention 2011;6:1037-45.

73. Sawada T, Shite J, Garcia-Garcia HM, Shinke T, Watanabe S, Otake H, Matsumoto D, Tanino Y, Ogasawara D, Kawamori H, Kato H, Miyoshi N, Yokoyama M, Serruys PW, Hirata K. Feasibility of combined use of intravascular ultrasound radiofrequency data analysis and optical coherence tomography for detecting thin-cap fibroatheroma. Eur Heart J 2008;29:1136-46.

74. Costopoulos C, Timmins LH, Huang Y, et al. Impact of Combined Plaque Structural Stress and Wall Shear Stress on Coronary Plaque Progression, Regression, and Changes in Composition. Eur Heart J 2019;40:1411-22.

75. Tarkin JM, Dweck MR, Evans NR, et al. Imaging Atherosclerosis. Circ Res 2016;118:750-69.

76. Jaffer FA, Calfon MA, Rosenthal A, et al. Two-dimensional intravascular near-infrared fluorescence molecular imaging of inflammation in atherosclerosis and stent-induced vascular injury. J Am Coll Cardiol 2011;57:2516-26.

Cite this article as: Kitahara S, Kataoka Y, Sugane H, Otsuka F, Asaumi Y, Noguchi T, Yasuda S. In vivo imaging of vulnerable plaque with intravascular modalities: its advantages and limitations. Cardiovasc Diagn Ther 2020;10(5):1461-1479. doi: $10.21037 /$ cdt-20-238 